\title{
The Effect of Some Immunological Indicators Associated with Systemic lupus erythematosus Disease
}

\author{
Wasan Abdulateef Majeed Al-Azzawi \\ College of Education for Pure Sciences / Diyala University \\ Iraq \\ Email: wasanabdulateef2015@gmail.com \\ DOI: 10.31364/SCIRJ/v6.i8.2018.P0818545 \\ http://dx.doi.org/10.31364/SCIRJ/v6.i8.2018.P0818545
}

\begin{abstract}
The current study was conducted on a sample of Iraqi patients with "'Systemic lupus erythematosus"( SLE) disease that affects the joints and kidneys. Blood tests were gathered from 32 patients with rheumatic ulcers, matured somewhere in the range of 13 and 50 years, with $96.87 \%$ of females. A total of 32 other blood samples of with Systemic lupus erythematosusin kidney disease were found between the ages of 16 and $\mathbf{6 5}$, of whom $90.62 \%$ were females. For the purpose of comparison, 32 other blood samples were collected from healthy individuals (control) between 21 and 54 years of age, 53.12\% of whom were females. The relationship between a number of immunological markers and the disease was studied, including the presence of antinuclear antibodies such as antigenpo (RPP), antigenSCI70 anti-antigen (AMA-M2), antigen (Jo1) and antigen PM-ScI. The results showed that none of these antibodies appeared in serum samples for healthy control, while they all appeared in serum samples for patients with "Systemic lupus erythematosus" diseasethat affects the joints and kidneys. The analytical tests gave a positive result for the serum antigenpo (RPP) of $43.75 \%, 31.25 \%$ of the aggregate number of patients with joints and kidneys separately, SCI70 antigen (18.75\% and 6.25\%) and antigen AMA-M2 (31.15\%). (15.62\% and $3.13 \%)$, antigens PM-ScI (34.37\% and $12.50 \%$ ) of the aggregate number of patients with joints and kidneys respectively, also, in light of these outcomes, the appearance of these antigens In the above percentages in the serum of the immunological indicators important to diagnose the Systemic lupus erythematosus diseasethat affects the joints and kidneys.
\end{abstract}

Key words: Systemic lupus erythematosus, anti-topoisomerase, systemic sclerosis, polymyositis.

\section{Introduction}

"Systemic lupus erythematosus" (SLE) is a systemic autoimmune disease with multiorgan inflammation. It is characterized by production of pathogenic autoantibodies and deposition of immune complexes in multiple organs, reflecting a worldwide loss of selftolerance [1] which then result in a wide array of clinical manifestations in skin, blood, kidney, joints, heart and central nervous system, and so on.[2]. It is a "chronic autoimmune disease" showing very heterogeneous clinical indications and multi-fundamental inclusion. Patients are vulnerable to backslide and abatement, in this manner making administration testing [3-4] . It usually affects women more often than men in a ratio of 8:1 approximately [5]. The peak age of SLE diagnosis ranges from 15 to 44 years old. Compared with other groups, women of child-bearing age are susceptible to the highest incidence of SLE.[6] The etiology of SLE still remains unclear, but it is generally accepted that the onset of SLE is a multifactorial combined result, involving environmental, genetic, age, and hormonal.[7]. Autoantibodies have a central role in (SLE). The presence of autoantibodies preceding disease onset by years has been reported both in patients with SLE and in those with rheumatoid arthritis, suggesting a gradual development of these diseases [8]. A trademark highlight of patients with fundamental immune system illnesses is the nearness of autoantibodies in their sera that objective intracellular parts [9]. A portion of these autoantibodies are valuable symptomatic markers for different fundamental immune system infections [10]. In excess of 100 autoantigens have been distinguished, which are focused by SLE autoantibodies [11]. The autoantigens that are focused via autoantibodies differ among SLE patients [12]. A few autoantibodies have awesome assorted variety in their pervasiveness among various races and nations [13-14]. In patients with SLE several autoantibodies are found, including anti- po(RPP ), anti-topoisomerase I (Scl-70), anti- AMA-M2, anti- Jo1 anti-PM/Scl antibodies [15] Autoantibodies represent a serological hallmark in the diagnosis of systemic autoimmune rheumatic diseases (SARD) such as systemic lupus erythematosus (SLE), systemic sclerosis (SSc), Sjögren's syndrome (SjS) or polymyositis (PM)[16].

Materials and methods of work

Laboratory tests and blood tests were performed in the laboratory of the Center for Disease and Kidney Transplantation and the laboratories of Ghazi Hariri Hospital. The blood samples were collected from the patients for the kidney group (32), for the group of 
joints (32), the healthy (32), taking another $3 \mathrm{ml}$ of the blood sample and placed in the plastic gel tubes and left at room temperature $\left(25^{\circ} \mathrm{C}\right)$ for $5-10$ minutes. The blood clot, then centrifuged at 4000 cycles / min for 5 minutes, then the serum was withdrawn. The serum samples were divided into three parts in the Eppendorf tubes and 500 microliters per test tube and frozen (-38 $\left.{ }^{\circ} \mathrm{C}\right)$ ) Until serological tests are carried out. The tests were carried out in the laboratories of the Faculty of Science and the biological research unit of the hot spots at the University of Baghdad and in the educational laboratories in Baghdad Medical City. These tests included All of the following:

Antinuclear antibody test.

This test was performed in IMTEC-ANA-LIA MAXX indirect method to measure IgG antibodies according to the method described previously. This test provides a differential diagnosis for various types of antibodies such as antigen PO (RPP), antigen SCI70, antigen AMA-M2, antigen Jo1 and antigen PM-ScI in serum or human plasma. This test was used several materials and tools and solutions are attached with Testing kit and equipped by German Human company.

\section{Preparation of solutions Washing Solution}

Add $1 \mathrm{ml}$ of $20 \mathrm{~mL}$ concentrated washing solution with $20 \mathrm{x}$ concentration to $19 \mathrm{ml}$ of distilled water to be $20 \mathrm{ml}$.

\section{Solution dilution models}

Prepare the solution by dissolving the contents of one DIL-LIA pack in $30 \mathrm{ml}$ of the prepared washing solution in the previous paragraph. Mix well and keep $5 \mathrm{~m}$ until use.

\section{Light Solution models}

The sample is diluted by 101: 1 by adding 10 microliters of serum to $1 \mathrm{ml}$ of the dilution solution in the previous step and kept at $5 \mathrm{~m}$ until use.

\section{The method of work}

Against atomic antibodies were assessed by the technique depicted by [17].

1. Test strip was placed in the brood dish and added $1 \mathrm{~mL}$ of the washing solution and incubated for one minute at $25 \mathrm{~m}$.

2. Remove the washing solution from the broth and wash the tape with $1 \mathrm{ml}$ of the washing solution and then put the plate containing the test strips in the vibrator motor for 5 minutes.

3. Remove the washing solution and rehash the washing stage three times.

Add $1 \mathrm{ml}$ of the mixed solution and incubate the special dishes $25^{\circ} \mathrm{C}$ for 30 minutes. Wash the strips with the wash solution ( $\left.1 \mathrm{ml}\right)$ and repeat the washing three times according to step (2).

5. Add $1 \mathrm{ml}$ of the base solution in the incubator and incubate the dishes $25^{\circ} \mathrm{C}$ for 10 minutes.

6. Remove the base solution and add $1 \mathrm{ml}$ of distilled water. Remove the ions for 25 minutes.

7. Remove the distilled water from the incubator dish and add $1 \mathrm{ml}$ of the reaction suspension solution to the incubator dish containing the test strip, which incubated $25^{\circ} \mathrm{C}$ for 5 minutes.

8. Remove the reaction-blocking solution and leave the strip to dry where the colored packets appear, each of which represents each of the 17 biochemical tests. Read the packages using the Transparent Evaluation Template provided by the company as shown in Figure (1). 


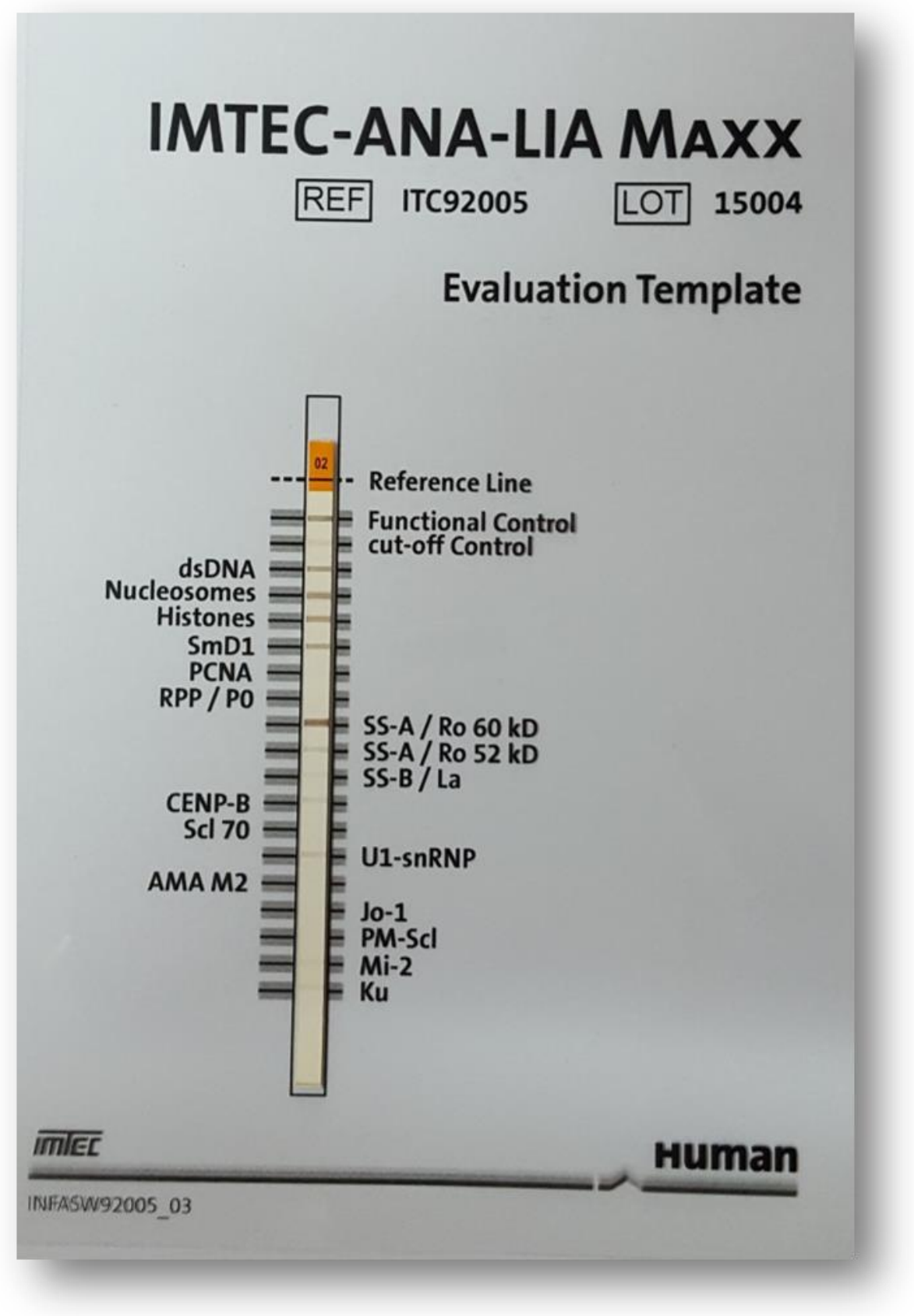

Figure (1): Standard evaluation template for self-sufficiency packages

\section{Methods of reading results}

The results were read by holding each test strip by means of the forceps supplied with the kit and placing it on the transparent evaluation mold. Each visible package has its location on its index. The visible packets were read and the results were recorded in the analysis form shown in Appendix 1.

\section{Statistical analysis}


Statistical Analysis System (SAS) (2012) was used to analyze the data for the study samples and to study the effect of the different parameters on the studied traits. The differences between the mean and the least significant difference were compared with the LSD.

\section{Results and discussion}

The investigation test comprised of two gatherings of patients with rheumatic ulcer ailment in a sum of 32 patients and reddish lupus, which affects the kidneys in a total of 32 patients. The two groups were compared to the healthy control group of 32 people.

\section{Antigen po (RPP)}

Antibodies directed against P-ribosomal proteins are specific and sensitive to patients with lupus erythematosus in the case of depression and psychosis, particularly in children with Systemic lupus erythematosus[18].

The results shown in Table( 1) indicate the presence of PO (RPP) antibodies in the blood vessels of only 14 of the 32 samples of patients withSystemic lupus erythematosus, where the test of the antibodies was given as a positive result of $43.75 \%$ (P <0.01) showed that the other 18 patients (negative result) did not appear in the same group. The results shown in Table (1) showed that the antibodies to po (RPP) ) In blood vessels 10 patients 31.25\% positive result for patients with "Systemic lupus erythematosus" that affects the kidneys and a significant difference In light of these results, this biomarker is not a strong clinical indicator of the incidence of (SLE) affecting the joints and kidneys .

Table 1: Investigation of PO (RPP) antibodies in blood samples of patients with systemic lupus erythematosuswhich affects the kidneys and joints compared to the healthy persons.

\begin{tabular}{|c|c|c|c|c|c|}
\hline \multirow[t]{2}{*}{ Chi-Square } & \multicolumn{2}{|c|}{ Negative (-) } & \multicolumn{2}{|c|}{ Positive $(+)$} & \multirow[t]{2}{*}{ Groups } \\
\hline & $\%$ & No. & $\%$ & No. & \\
\hline$* * 10.52$ & 68.75 & 22 & 31.25 & 10 & Kidneys \\
\hline$* 4.96$ & 56.25 & 18 & 43.75 & 14 & Joints \\
\hline$* * 15.00$ & 100.0 & 32 & 00.0 & 0 & Control \\
\hline--- & \multicolumn{2}{|c|}{$* * 10.36$} & \multicolumn{2}{|c|}{$* * 10.36$} & Chi-square \\
\hline \multicolumn{6}{|c|}{.$(\mathrm{P}<0.01) * * ،(\mathrm{P}<0.05) *$} \\
\hline
\end{tabular}

The results were steady with the discoveries [18] of of an investigation of a gathering of patients withsystemic lupus erythematosus where antibodies against po (RPP) were found in the serum of patients with lupus, which distinguished lupus erythematosus in youngsters with the disease. The presence of antibodies is not limited to children infected with the disease and psychosis, but to the rest of the patients and the existence of evidence of the activity of the disease. Numerous investigations have affirmed the part of antibodies directed against nerve cells and generators of nuclear antibodies where their presence has a relationship with inflammation of the nervous system In patients with (SLE) [19]. In a study [20] they confirmed the presence of antibodies against po (RPP) in patients with nephrotic nephritis but less than in patients with (SLE). The presence of antibodies in patients with lupus erythematosus is associated with psychosis, where there is a relationship between lupus patients with psychosis and the activity of the disease and the cause of these antibodies, the mechanism of action can prevent the synthesis of protein leads to a defect in the brain. This study is the first local study to investigate the antibodies to po (RPP) in the serum of patients with lupus erythematosus that affects the joints and kidneys.

\section{Antigen SCI70}

Of the sub-antibodies found in the solubility of patients withsystemic lupus erythematosus shows a relationship between disease activity and its presence may indicate an increased risk of pulmonary hypertension and nephritis.

The results shown in Table (2) show that SCI70 antibodies in the blood vessels of only six of the 32 samples of patients with systemic Lupus erythematosus in join were present in the blood vessels. The test of the antibodies was given as a positive result of $18.75 \%$ in the patients' ( $\mathrm{P}<0.01$ ) showed that $26 \%$ of these patients had no antibodies in their blood vessels (negative result) within the same group. The results shown in Table 2 show that SCI70 antibodies were present in only 2 blood vessels Of the patients' samples showed a $6.25 \%$ positive outcome for patients with lupus erythematosus $(\mathrm{P}<0.01)$ than the rest of the 30 patients in the same group with the 
disease. These antibodies did not appear in their blood vessels (negative result). The antibodies did not appear in any sample of the control group (negative result). In light of these results, this indicator is not a clinical indicator of the incidence of lupus erythematosus affecting the jointsandkidneys.

These results are consistent with the findings of a study conducted on a group of patients with lupus erythematosus, where they affirmed that the nearness of these antibodies in the serum is a demonstrative confirmation of fundamental scleroderma. Therefore, it is possible to distinguish between the patient suffering from skin sclerosis or lupus erythematosus In the case of antibodies against SCI70 in patients withsystemic lupus erythematosus and at a very low rate, these antibodies are linked to DNA and DNA proteins [23].

Table 2: Investigation of anti-antibodies SCI70 in blood samples for patients with (SLE) which affects the kidneys and joints compared to the healthy persons.

\begin{tabular}{|c|c|c|c|c|c|}
\hline \multirow[t]{2}{*}{ Chi-Square } & \multicolumn{2}{|c|}{ Negative (-) } & \multicolumn{2}{|c|}{ Positive (*) } & \multirow[t]{2}{*}{ Groups } \\
\hline & $\%$ & No. & $\%$ & No. & \\
\hline$* * 14.38$ & 93.75 & 30 & 6.25 & 2 & Kidneys \\
\hline$* * 13.19$ & 81.25 & 26 & 18.75 & 6 & Joints \\
\hline$* * 15.00$ & 100.0 & 32 & 0.00 & 0 & Control \\
\hline$-\overline{--}$ & \multicolumn{2}{|c|}{$* * 12.50$} & \multicolumn{2}{|c|}{$* * 6.27$} & Chi-Square \\
\hline \multicolumn{6}{|c|}{.$(\mathrm{P}<0.01) * *$} \\
\hline
\end{tabular}

\section{Antigen of AMA-M2}

Antibodies against mitochondria are found in patients with autoimmune diseases, in particular cirrhosis of the biliary cirrhosis [24].

The results shown in Table( 3) indicate that AMA-M2 antibodies in the blood vessels of only 10 of the 32 samples of patients with (SLE) in the joints. The test of the antibodies was given as a positive result $31.15 \%$ in the samples of the patients studied (P < 0.01 ) from alternate patients who did not demonstrate these these antibodies in their blood vessels and the 22 (negative result) within the same group, and the results shown in table (3) to the emergence of antibodies AMA-M2 Only 6 of the patient samples had a blood serum of $18.75 \%$ positive for patients withsystemic lupus erythematosusin Kidneysin the samples of the patients studied (P < 0.01 ) from the other patientswho did not show these antibodies in their blood vessels and the 26 (negative result) within the same group, These antibodies were not shown in any sample of healthy control group (negative result). In light of these results, this indicator is not a clinical indicator of the incidence of lupus erythematosus affecting the kidneys and joints. These results confirm that these antigens are not considered a vital indicator for the diagnosis of lupus erythematosus. There are no past investigations on the impact of these antigens on red lupus erythematosus.

Table 3: Investigation of (AMA-M2) in patients in blood samples for patients with systemic lupus erythematosus, which affects the kidneys and joints compared to the healthy persons

\begin{tabular}{|c|c|c|c|c|c|}
\hline \multirow[t]{2}{*}{ Chi-Square } & \multicolumn{2}{|c|}{ Negative (-) } & \multicolumn{2}{|c|}{ Positive $(+)$} & \multirow[t]{2}{*}{ Groups } \\
\hline & $\%$ & No. & $\%$ & No. & \\
\hline$* * 13.19$ & 81.25 & 26 & 18.75 & 6 & Kidneys \\
\hline$* * 10.42$ & 68.85 & 22 & 31.15 & 10 & Joints \\
\hline
\end{tabular}




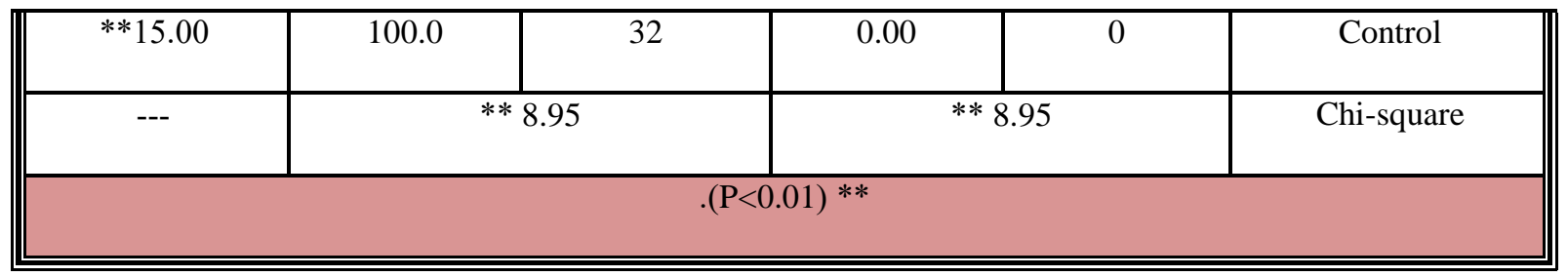

\section{Antigen Jo1}

The antibodies against hoostal (Jo1) are clinically beneficial in autoimmune diseases, in particular Myositi, or Antisynthetis Syndrome (ASS). These antigens are also found in many autoimmune diseases, such as coronary heart disease ILD) Inflammatory Muscle Disease and can appear with antibodies that appear with immunological diseases [25].

The results shown in Table (4) indicate that Jo1 antibodies in blood serotonin showed only 5 of the 32 samples of patients with systemic Lupus erythematosus in the joints. The test of these antibodies was given positive result of $15.62 \%$ in the samples of patients included in the accompanying study $(\mathrm{P}<0.01)$ ) of alternate patients who did not demonstrate these antibodies in their blood vessels and the 27 (negative result) within the same group, and the results shown in table (4) to the emergence of antibodies Jo1 in only one blood serum Of the patients were $3.13 \%$ positive for patients with lupus erythematosus in kidneys, These antibodies were not shown in any sample of healthy control group (negative result). In light of these results, this indicator is not a clinical indicator of the incidence of (SLE) affecting the joints and kidneys.

There is no past investigations on the nearness of antigens Jo1 systemic lupus erythematosusrelationship Although there are studies that confirm the presence of these antigens in sera of patients with autoimmune diseases and The Idiopathic Inflammatory Myopathies (IIM) and all autoimmune disorders including diseases in that muscle inflammation polymyositis (PM) and dermatomyositi (DM) anddermatomyositi associated with malignant diseases and many connective tissue Diseases [26].

Table (4). Investigation of antibodies against Jo1 in blood samples of patients with (SLE) affecting the kidneys and joints compared to healthy control

\begin{tabular}{|c|c|c|c|c|c|}
\hline \multirow[t]{2}{*}{ Chi-Square } & \multicolumn{2}{|c|}{ Negative (-) } & \multicolumn{2}{|c|}{ Positive (+) } & \multirow[t]{2}{*}{ Groups } \\
\hline & $\%$ & No. & $\%$ & No. & \\
\hline$* * 14.78$ & 96.87 & 31 & 3.13 & 1 & Kidneys \\
\hline$* * 13.59$ & 84.38 & 27 & 15.62 & 5 & Joints \\
\hline$* * 15.00$ & 100.0 & 32 & 0.00 & 0 & Control \\
\hline--- & \multicolumn{2}{|c|}{$* 5.26$} & \multicolumn{2}{|c|}{$* 5.26$} & Chi-square \\
\hline \multicolumn{6}{|c|}{$* *(\mathrm{P}<0.01)$} \\
\hline
\end{tabular}

\section{Antigen PM-ScI}

Antigens are associated with autoimmune diseases and in particular muscle inflammation and scleroderma [27].

The results shown in Table (5) indicate that PM-Sci antibodies in the blood vessels of 11 of the 32 samples of patients with (SLE) in the joints were found to be positive. $34.3 \%$ of the patients in the study were positive $(\mathrm{P}<.01)$ ) from alternate patients who did not demonstrate these antibodies in their blood vessels of the 21 samples (negative result) within the same group, as the results shown in Table (5) to the emergence of antibodies PM-ScI in Blood Serum Only four of the patient samples are 12.50\% positive for patients with lupus erythematosusin kidneys, These antibodies were not shown in any sample of healthy control group (negative result). In 
light of these results, this indicator is not a clinical indicator of the incidence of systemic lupus erythematosus affecting the jointsandkidneys

These results show that PM-Sci antigens do not represent a chemo-positive indicator of (SLE). Studies of this disease have been associated with autoimmune disease as a scleroderma disease. Low levels of these antigens have been found in various CTDs but high levels are found to be restricted Its presence ispolymyositis, dermatomyositand Myositi[28].

Table 5:Investigationof antibodies against PM-ScI in blood samples of patients with (SLE) that affects the kidneys and joints compared with healthy controls

\begin{tabular}{|c|c|c|c|c|c|}
\hline \multirow[t]{2}{*}{ Chi-Square } & \multicolumn{2}{|c|}{ Negative (-) } & \multicolumn{2}{|c|}{ Positive $(+)$} & \multirow[t]{2}{*}{ Groups } \\
\hline & $\%$ & No. & $\%$ & No. & \\
\hline$* * 13.84$ & 87.50 & 28 & 12.50 & 4 & Kidneys \\
\hline$* * 9.75$ & 65.63 & 21 & 34.37 & 11 & Joints \\
\hline$* * 15.00$ & 100.0 & 32 & 0.00 & 0 & Control \\
\hline--- & \multicolumn{2}{|c|}{$* * 9.17$} & \multicolumn{2}{|c|}{$* * 9.17$} & Chi-square \\
\hline \multicolumn{6}{|c|}{.$(\mathrm{P}<0.01) * *$} \\
\hline
\end{tabular}

\section{Conclusions}

Based on our findings in the above search results, antibodies including anti-po (RPP), anti-topoisomerase I (Scl-70), anti-AMA-M2, anti-Jo1 anti-PM / Scl antibodies in serum For patients with lupus erythematosus is a diagnostic evidence of the presence of the disease, but is an indication of the existence of other autoimmune diseases and is not related to the disease, either patients with lupus erythematosus that affects the joints or the lupus erythematosus that affects the kidneys and this prompts the trial of discovery of the infection does not require disclosure About these antibodies to accomplish the target of genuine finding as soon as possible and not to shadowed results and reach the new curing goals for the disease.

\section{References}

1. Choi, J.; Kim, ST.; Craft, J..(2012)The pathogenesis of systemic lupus erythematosus. Curr. Opin Immunol 24:651-7.

2. Lau, CS.; Yin, G.; Mok, MY.(2006). Ethnic and geographical differences in systemic lupus erythematosus: an overview. Lupus;15:715-719.

3. Hu, W.; Niu, G.; Lin, Y.(2016 ). Impact of the polymorphism in vitamin D receptor gene B smI and the risk of systemic lupus erythematosus: an updated meta-analysis. Clin Rheumatol ;35:927-34.

4. Kamal, A.; Khamashta ,M. (2014) The efficacy of novel B cell biologics as the future of SLE treatment: a review. Autoimmun Rev.; 13(11): 1094-101.

5. Mahler, M.; Miyachi, K.; Peebles, C.; Fritzler, M.(2012) The clinical significance of autoantibodies to the proliferating cell nuclear. Autoimmunity Reviews $11: 771-775$.

6. Rahman, A. Isenberg, D.A. (2008) Systemic lupus erythematosus.N Engl J Med; 358 (9): 929-39.

7. Tsokos, G.C. Systemic lupus erythematosus.(2011) N Engl J Med; 365:2110-21. 
8. Moulton, V.; Fueyo, A.; Meidan, E.; Li, H.; Mizui, M.; and Tsoko, G. Pathogenesis of Human Systemic Lupus Erythematosus: A Cellular Perspective. (2017).Trends Mol Med ; 23(7): 615-635.

9.Tan, EM;. Antinuclear antibodies: diagnostic markers for autoimmune diseases and probes for cell biology.(1989) Adv Immunol.;44:93-151.

10. Muro, Y.; Antinuclear antibodies.(2005) Autoimmunity.;38:3-9

11.Sherer, Y.; Gorstein, A.; Fritzler, MJ.; Shoenfeld, Y. Autoantibody explosion in systemic lupus erythematosus: more than 100 different antibodies found in SLE patients.(2004) Semin Arthritis Rheum;34:501-37.

12.Pradhan, V.; Patwardhan, M.; Ghosh, K. (2010) Anti-nucleosome antibodies as a disease marker in systemic lupus erythematosus and its correlation with disease activity and other autoantibodies; Indian J Dermatol Venereol Leprol; 76:145-9.

13. Satoh, M.; Vazquez-Del Mercardo, M.; Chan, E.; Clinical interpretation of antinuclear antibody tests in systemic rheumatic diseases.(2009) Mod Rheumatol.;19:219-28.

14. Krzyszczak, ME.; Li, Y.; Ross, SJ.; Ceribelli, A.; Chan ,EK.; Bubb, MR. Gender and ethnicity differences in the prevalence of scleroderma-related autoantibodies .Clin Rheumatol.;30:1333-9

15. Koenig, M.; Dieudé, M.; Senécal, JL.(2008). Predictive value of antinuclear autoantibodies: the lessons of the systemic sclerosis autoantibodies. Autoimmun Rev;7:588-93.

16. Petri, MH.; Satoh, M.; Martin-Marquez, BT.; Vargas-Ramirez ,R.; Jara, LJ.; Saavedra, MA. (2013) Implications in the difference of anti-Mi-2 and -p155/140 autoantibody prevalence in two dermatomyositis cohorts from MexicoCity and Guadalajara. Arthritis Res Ther.;15:R48.

17. Conrad, K.(2002). Autoantibodies in Systemic Autoimmune Diseases-A Dignosticr Reference; pabst science publishers, lengerich.Berlin,Riga, Rom,Viernheim,Wien,Zagreb. NLM ID: 101182698 [Book].

18. Press, J .; Palayew, K .; Laxer, RM.; Kelon, K.; Eddy,A.; Rakoff, D.; and Silverman, ED.(1996) . Antiribosomal p antibodies in pediatric patients with systemic lupus erthematosus and psychosis. Arthritis \&Rheumatism 39:671-676.

19. Bluestein, HG.;Williams, GW.; Steinberg, AD. (1981). Cerebrospinal fluidantibodies to neuronal cells: associastion with neuropsychiatric manifestations of systemic lupus erythematosus. Am J Med70:240-246.

20.Bonfa, E.; and Elkon, EB.(1986) Clinical and serologic associations of the antiribosomal P protein antibody. Arthritis Rheum 29:981-985.

21. Stacey, DW.; Skelly, S.; Watson, T.; Elkon, K.; Weissbach, H.; Brot, N. (1988). The inhibition of protein synthesis by IgG containing anti-ribosome $\mathrm{P}$ autoantibodies from systemic lupus erythematows patients. Arch Biochem Biophys 267:398-403.

22.Mahler, M. and Fritzler, M. (2010). Epitope specificity and significance in systemic autoimmunediseases. Ann .NY Acad. Sci.1183:267-87.

23.Gussin, HA.; Ignat, GP.; Varga, J.; Teodorescu, M.(2001). Anti-topoisomerase I (anti-Scl-70) antibodies in patients with systemic lupus erythematosus. Arthritis Rheum ;44:376-83.

24.Tan, Z.; Zhou, Y.; Li ,X.; Wang, G.; Tao, J.; Wang ,L.; Ma ,Y.; Li, X.(2018) . Brain magnetic resonance imaging, cerebrospinal fluid, and autoantibody profile in 118 patients with neuropsychiatric lupus.Clin Rheumatol.;37(1):227-233. doi: 10.1007/s10067-017-3891-3.

25. Mennesson ,EG.; Fabien, N .; Cordier, JF.; Ninet, J.; Tebib, J and Rousset, H.(2007) Clinical significance of anti- Histidyl -tRNA synthetase (Jo1)Autoantibodies. Ann .NY Acad. Sci. 1109:414-420. 
26.Mileti, LM.; Strek, ME.; Niewold, TB.; Curran ,JJ. and Sweiss, NJ .(2009). Clinical characteristics of Patients with AntiJO1antibodies: Asingie center Experience:J Clin Rheumatol,15(5): 254-255 .

27. Meyer, O.; Chaisemartin, L.; Nicaise-Roland ,P.; Cabane, J.; Tubach, F.; Dieude, P.(2010). Anti-RNA polymerase III antibody prevalence and associated clinical manifestations in a large series of French patients with systemic sclerosis: a cross-sectional study. $\mathbf{J}$ Rheumatol.;37:125-30.6.

28.Maes, L.; Blokmans, D.; Verschueren ,P.; Westhovens, R.; Beeck, K. (2010). Vermeersch P, Bergh K, Burlingame R, Mahler M, Bossuyt X: Anti-PM/Scl-100 and anti-RNA-polymerase III antibodies in scleroderma: clinica chimica Acta, 411: 965-971.

Appendix 1

\section{Nucleus antibody analysis form}

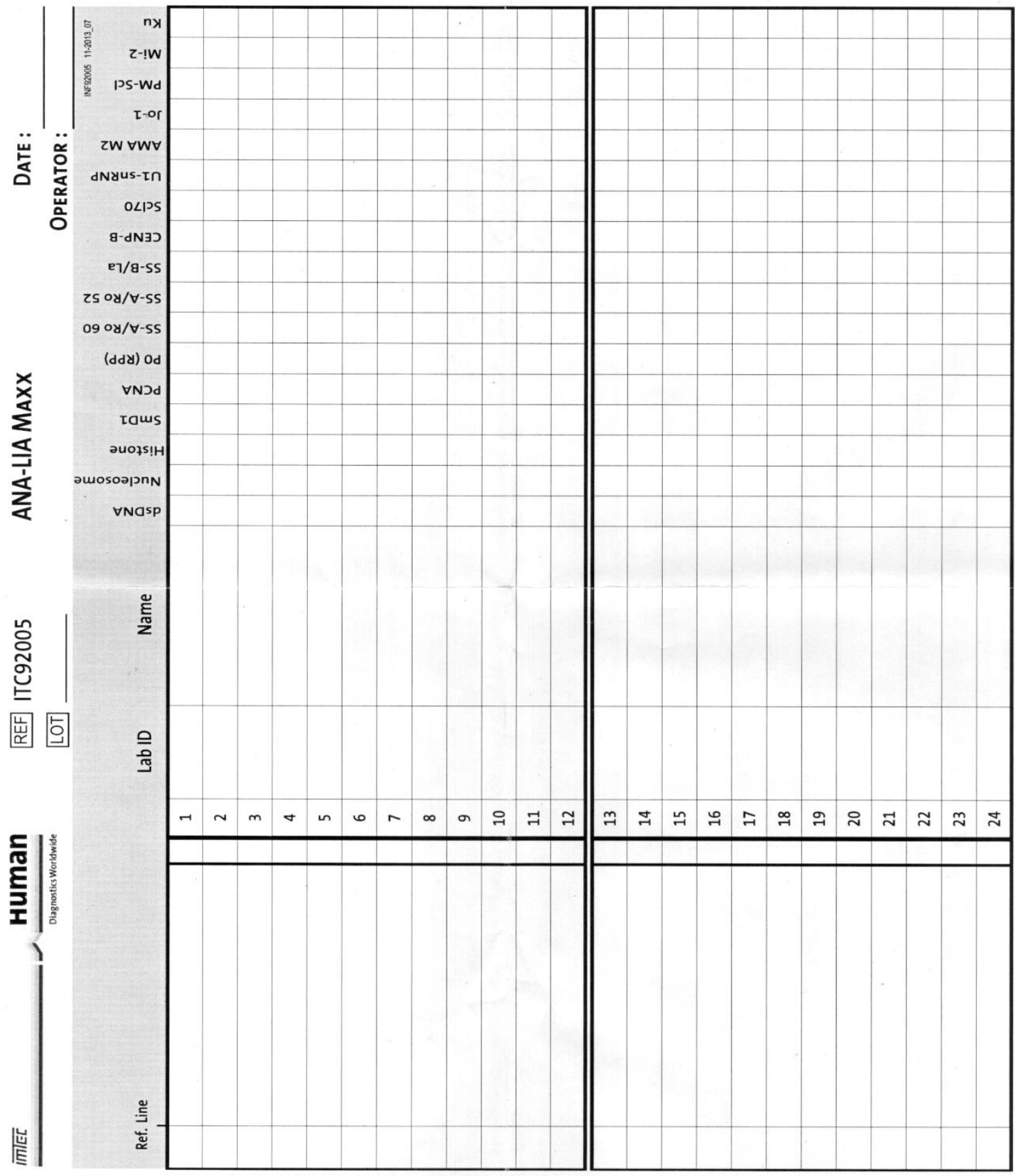

Www.scirj.org 